\title{
Selection of a Suitable Service Measure and Determination of LOS Criteria for Indian Multilane Interurban Highways: A Methodological Review
}

\author{
Ashutosh Arun ${ }^{1}$ Erramapalli Madhu' ${ }^{2}$ Senathipathi Velmurugan ${ }^{1}$
}

Received: 3 August 2015/Accepted: 22 June 2016/Published online: 30 June 2016

(C) Springer International Publishing Switzerland 2016

\begin{abstract}
Any transport facility is essentially a service being provided to the society. Therefore, it is expected of the traffic engineers, transport planners and policy-makers alike to be able to understand and evaluate the quality of service that is being provided by the transport facilities designed by them. The level-of-service (LoS) concept was devised in the US Highway Capacity Manual (US-HCM) precisely for the above consideration. However, direct implementation of the US-HCM methods in India is not possible because of the heterogeneous traffic conditions and vastly unique driver behavior found on Indian highways. Therefore, it becomes imperative to evaluate other competing methodologies that may be more appropriate in defining the LoS being offered to the road users by Indian highways in general and multilane interurban highways in particular. Towards this end, this paper reviews in detail the LoS estimation methodologies that have been demonstrated to be suitable for application in traffic scenarios characterized by high heterogeneity and lane indiscipline. Also, based on an exhaustive review of the literature, the study recommends that three to five categories of LoS in the stable-flow region may be explored for practical application in the Indian scenario as part of the ongoing research on development of an Indian Highway Capacity Manual.
\end{abstract}

Ashutosh Arun

ashutosharun.87@gmail.com

1 Traffic Engineering and Safety Division, CSIR-Central Road Research Institute, New Delhi 110025, India

2 Transportation Planning Division, CSIR-Central Road Research Institute, New Delhi 110025, India
Keywords Highway capacity $\cdot$ National highways $\cdot$ Level of service $\cdot$ Service measures

\section{Introduction}

All around the world and especially in the developed nations a consensus is evolving that the design, upgrade and even maintenance of a transport facility should be largely demand-based. This demand is expected to itself emanate from the perceptions and aspirations of the endusers of that facility. From Indian perspective, traditionally, the definition of the needs of a transport facility has been largely top-driven and ad hoc in nature. However, gradually this new awakening regarding the user-driven approach of defining needs is finding its way into the general conscience of the designers, planners and policymakers in India as well. Recognizing this need of understanding the perception of a user about the transport facility the researchers in the US devised the concept of level of service (LoS). LoS was a novel concept when it was first introduced in the 1965 version of the US-Highway Capacity Manual (US-HCM). Over the years, however, several researchers have expounded and refined the LoS concept and it subsequently found its way in one form or the other in the highway capacity manuals developed in other parts of the world. Similarly, the results emanating out of this paper on LoS can find a place in the ongoing sponsored network project titled, "Development of Indian Highway Capacity Manual" (Indo-HCM) being sponsored by Council of Scientific and Industrial Research (CSIR) and spearheaded by CSIR-Central Road Research Institute, New Delhi (CSIR-CRRI).

The objective of this paper is to aid in formulating a methodological framework for the estimation of LoS for 
multilane interurban highways of India whereby the appropriate method can be devised for adoption in IndoHCM project in respect of the above class of roads. Thus, the paper encapsulates the aspects of selection of suitable service measure(s) and defining the LoS criteria itself by reviewing relevant studies carried out in India and abroad. Additionally, any new method or concept other than LoS brought out to measure the performance of a road section and which was found suitable for possible application to highways in India have also been discussed.

The paper has been organized in seven sections. First section gives an introduction to the problem being addressed by this paper. "Definition of Level of Service and Characteristics of Service Measures" gives the definition of LoS as given by US-HCM and the general characteristics of a suitable service measure for measuring the quality of service (QoS) of a roadway facility. "Review of LoS Criteria with Different Service Measures" presents the review of LoS methods found suitable for possible application on multilane interurban highways in India. In "LoS Determination Based on Fuzzy Logic", an argument has been furthered regarding the use of fuzzy logic in the definition of LoS criteria. In "Selection of Suitable Method for Indian Traffic Conditions", the service measures discussed in the previous section are critically evaluated with regard to their applicability on Indian multilane highways. A further discussion on the number of LoS categories suitable for Indian multilane highways is presented in "Number of LoS Categories Required". Final section presents the conclusions drawn from the study.

\section{Definition of Level of Service and Characteristics of Service Measures}

The US-HCM defines two concepts to assess the performance of a transport facility viz. $Q o S$ and $L o S$. While QoS describes perception of the travelers of the performance of a transport facility, the $\operatorname{LoS}$ is essentially a quantitative stratification of service measure(s) representing the equality of service [1] and thereby describing the operating conditions within a traffic stream.

For a highway facility, the US-HCM defines six levels of service ranging from $\operatorname{LoS} \mathrm{A}$ to $\mathrm{F}$ representing various service conditions ranging from free-flow conditions to the point of breakdown of vehicular flow. To arrive at such a categorization of traffic operational conditions, it is essential to identify either one or a few service measures that can adequately capture the QoS being provided by a road facility. The succeeding section describes the characteristics of a suitable service measure.

The performance of a road facility can be evaluated on the basis of several performance measures that seek to define the operating conditions of a traffic stream. However, observing and controlling for each of those performance measures to arrive at the quantification of drivers' perception about service quality is neither feasible nor desirable. Accordingly, the highway capacity manuals worldwide have focused on one or more service measures that are easy either to observe in the field or estimate from field observed data, and give a reasonably good estimate of the perceived QoS for any given road facility.

The selection of a suitable service measure is an important issue considering the step-function nature of LoS. This means that under boundary situations, even a marginal change in the value of the selected service measure can result in the transition of LoS output from one level to another resulting in a wholly different assessment of the traffic flow situation. This aspect of LoS can prove critical if one intends to measure the performance of any road facility solely on the basis of LoS. In order to circumvent this problem, the US-HCM elaborates the need for the estimation of certain other useful performance measures that are recommended to be considered along with the LoS while assessing the QoS [1]. The US-HCM lists the following desirable characteristics to be considered while selecting the service measure for any road facility [1]:

- It should reflect perception of the drivers on the performance of the facility.

- It should be controllable by the operating agency.

- It should be directly measurable in the field or estimable given a set of known field conditions.

Taking into consideration the above yardsticks, the USHCM has traditionally adopted traffic density in passenger car (pc)/kilometer/lane (i.e. pc/mi/lane in case of US-HCM, 2010) as the primary performance measure (or service measure) for defining the LoS of automobile modes on multilane highways. However, it is an established fact that the perception of driver about the QoS are influenced by his/her individual cultures and concerns which vary over geographical regions. Thus, the universality of a single (or even a set of) service measure seems impossible. The choice of service measures and the thresholds of LoS exhibited wide variations across various studies carried out throughout the world and the succeeding section provides a review of the same.

\section{Review of LoS Criteria with Different Service Measures}

In this section, studies from India and abroad dealing with the definition of $\operatorname{LoS}$ according to various service measures, or proposing alternate methods for assessing the QoS 
of a highway facility is reviewed with specific focus towards their applicability for multilane highways in India.

\section{LoS with Density as Service Measure}

Traffic density in a particular road section provides a direct picture of the operating conditions in that section. As the density increases, the maneuverability, journey speed and perceptions about safety decrease. The driver can clearly perceive congestion increasing with increasing density. Therefore, density was considered a good service measure to define LoS for multilane highway segments. A typical LoS criterion corresponding to FFS of $100 \mathrm{~km} / \mathrm{h}$ as per USHCM for multilane highways on the basis of density and other performance measures are given in Table 1 [2].

\section{LOS with Travel Speed as Service Measure}

For urban street segments, which can be multilane in configuration, the US-HCM lists travel speed (as a percentage of the base free-flow speed) of the through vehicle along with the volume-to-capacity $(V / C)$ ratio for through movement at the downstream boundary intersections as the service measures of choice [1]. The rationale behind this analogy is that the running speeds of through vehicles reflect all the factors such as operational delays that affect the movement of vehicles in that segment, while the volume-to-capacity ratio helps in determining whether breakdown of traffic flow had occurred in the road segment at the time of observation. The criteria devised by US$\mathrm{HCM}$ on the basis of these service measures are provided in Table 2 [1].

\section{LoS with Demand-Supply Ratio as Service Measure}

In traffic engineering, traffic volume represents the traffic demand ${ }^{1}$ for a particular transport facility at a given point of time, while capacity of that facility stands for the supply-side factor. Therefore, several studies have been attempted to use the volume-to-capacity ratio as a service measure. Using volume-to-capacity $(V / C)$ ratio as the service measure, Patel and Joshi attempted to determine the LoS thresholds based on $K$-means clustering of the $V /$ $C$ ratio [3]. The data for the exercise was collected on a typical six-lane divided urban carriageway in the city of Surat, India. They obtained six optimum clusters based on the $K$-means clustering approach, and the derived LoS criteria are provided in Table 3.

\footnotetext{
${ }^{1}$ In cases where the traffic volume is less than the capacity of the transport facility.
}

Table 1 LoS criteria for multilane highways as per US-HCM [2]

\begin{tabular}{lllll}
\hline LoS & $\begin{array}{l}\text { Free-flow } \\
\text { speed } \\
(\mathrm{km} / \mathrm{h})\end{array}$ & $\begin{array}{l}\text { Maximum } \\
\text { density } \\
(\mathrm{pc} / \mathrm{km} / \mathrm{lane})\end{array}$ & $\begin{array}{l}\text { Volume-to- } \\
\text { capacity } \\
\text { ratio }(\mathrm{V} / \mathrm{C})\end{array}$ & $\begin{array}{l}\text { Service flow } \\
\text { rate } \\
(\mathrm{pc} / \mathrm{h} / \mathrm{lane})\end{array}$ \\
\hline $\mathrm{A}$ & 100 & 7 & 0.32 & 700 \\
$\mathrm{~B}$ & & 11 & 0.50 & 1,100 \\
$\mathrm{C}$ & & 16 & 0.72 & 1,575 \\
$\mathrm{D}$ & & 22 & 0.92 & 2,015 \\
$\mathrm{E}$ & & 25 & 1.00 & 2,200 \\
\hline
\end{tabular}

Table 2 LoS criteria for urban street segments as per US-HCM

\begin{tabular}{lll}
\hline $\begin{array}{l}\text { Travel speed as a } \\
\text { percentage of base } \\
\text { free-flow speed }(\%)\end{array}$ & \multicolumn{2}{l}{ LoS by volume-to-capacity $(V / C)$ ratio } \\
\cline { 2 - 3 }$>8 / C \leq 1.0$ & $V / C>1.0$ \\
\hline 85 & $\mathrm{~A}$ & $\mathrm{~F}$ \\
$67-85$ & $\mathrm{~B}$ & $\mathrm{~F}$ \\
$50-67$ & $\mathrm{C}$ & $\mathrm{F}$ \\
$40-50$ & $\mathrm{D}$ & $\mathrm{F}$ \\
$30-40$ & $\mathrm{E}$ & $\mathrm{F}$ \\
$\leq 30$ & $\mathrm{~F}$ & $\mathrm{~F}$ \\
\hline
\end{tabular}

Table 3 LoS criteria for a typical six lane divided urban carriageway, Surat, India

\begin{tabular}{ll}
\hline LoS & \multicolumn{1}{l}{$V / C$ ratio } \\
\hline A & $<0.125$ \\
B & $0.125-0.276$ \\
C & $0.276-0.479$ \\
D & $0.479-0.715$ \\
E & $0.715-1.000$ \\
F & $>1.000$ \\
\hline
\end{tabular}

\section{LoS with Congestion as Service Measure}

Congestion was considered as a service measure for assessing LoS on midblock sections of urban roads in India by Maitra et al. [4]. The line of reasoning adopted for doing so was that while the volume-related characteristics such as traffic volume and roadway capacity can be considered as the causative factors behind congestion, the operational factors of a traffic stream such as delay and lower operating speeds were the net effects of congestion. Thus it was inferred that the consideration of the term 'congestion' alone as a service measure can address both the volumebased and operations-based characteristics.

The loss in freedom of movement $\left(\mathrm{LF}_{\mathrm{L}}\right)$ was quantified as the area under the speed-flow envelope (between the free-flow operation and the actual operating condition). Eventually, congestion $\left(\mathrm{CG}_{\mathrm{V}}\right)$ was defined as the percentage loss in freedom of movement under the prevailing 
roadway, traffic, and control conditions [4]. Based on the above definitions, the congestion was quantified to be $0 \%$ at free-flow and $100 \%$ at near-capacity flow conditions. It was reported that the flows above capacity result in forcedflow behavior where the quantified congestion can be said to be over $100 \%$. Mathematically, the congestion was defined as below:

$\mathrm{CG}_{\mathrm{V}}=\left(\frac{V}{V_{\mathrm{L}}}\right)^{b+1} \times 100 \%$

$b=\sum p_{i} m_{i}$

$V_{\mathrm{L}}=\left[\frac{1}{a}\left(1-\frac{S_{\mathrm{L}}}{S_{\mathrm{f}}}\right)\right]^{1 / b}$

where $p_{i}=$ proportion of vehicle type ' $i$ ' in the stream, $S_{\mathrm{f}}=$ free-flow speed of the stream in $\mathrm{km} / \mathrm{h}, V=$ operating traffic volume in PCU per hour, $V_{\mathrm{L}}=$ traffic volume at $100 \%$ congested conditions in PCU per hour, $S_{\mathrm{L}}=$ stream speed at $100 \%$ congested conditions in $\mathrm{km} / \mathrm{h}$, and $a$ and $m_{i}$ $(i=1,2, \ldots, n)$ are parameters to be calibrated from the observed data with $n$ being the total number of vehicletypes in the traffic stream. The coefficient $m_{i}$ indicates the contribution of the proportion of vehicle type $i$ in reducing the speed of any vehicle-type say from ' $S_{\mathrm{f}}$ ' to ' $S$ ' corresponding to the operating traffic volume $V$. As such, the term ' $S$ ' was modeled using the standard BPR model given in Eq. (4) which was subsequently used for the calibration of the values of $a$ and $m_{i}$ :

$S=S_{\mathrm{f}}\left[1-a\left(\frac{V}{C}\right)^{\sum p_{i} m_{i}}\right]$

where $C=$ capacity of the road section in PCU per hour.

Considering the fact that the operating conditions tend to degrade non-uniformly with the increasing congestion and thus in order to represent the variation of LoS based on traffic congestion in a comprehensive manner, ten different LoS categories were proposed. These included congestion levels of $5,10,20,30,40,50,60,80$, and $100 \%$ thereby defining nine $\operatorname{LoS}(\mathrm{A}-\mathrm{I})$ within the stable flow zone and one $\operatorname{LoS}(\mathrm{J})$ with congestion more than $100 \%$, indicating unstable (forced) flow [4]. The models were applied for four, six and eight-lane divided urban carriageways in the city of Mumbai and it was found that the models exhibited overall good goodness-of-fit coupled with low mean absolute error values when estimated and observed stream speeds were compared.

Anjaneyulu and Nagaraj [5] also quantified congestion as a measure of effectiveness for defining the concept of LoS. They attempted to define congestion on speed-based parameters. In this regard, congestion was quantified on a scale of $0-100$ as a combination of two parameters viz.
Table 4 LoS criteria for a typical four lane divided urban carriageway in Calicut, India

\begin{tabular}{lllr}
\hline LoS & \% Congestion & CV & Mean speed \\
\hline A & $0-25$ & $0-1.9$ & $0.95 \times V_{\mathrm{f}}$ \\
B & $25-55$ & $1.9-8.6$ & $0.80 \times V_{\mathrm{f}}$ \\
C & $55-80$ & $8.6-22$ & $0.70 \times V_{\mathrm{f}}$ \\
D & $80-100$ & $22-5.7$ & $0.65 \times V_{\mathrm{f}}$ \\
E & $>100$ & $5.7->22$ & $<0.65 \times V_{\mathrm{f}}$ \\
\hline
\end{tabular}

Coefficient-of-variation of speed (CV) and the mean speed normalized by free-flow speed $\left(V_{\mathrm{f}}\right)$. They carried out their study for urban roads in the city of Calicut in India. LoS criteria evolved for the four-lane divided urban carriageways in the above study are given in Table 4 [5].

\section{LoS Based on Platoon Characteristics as Service Measures}

Using platoon characteristics as performance measures, Surasak et al. [6] developed LoS for multilane highways in Japan. They argued that the present definition of LoS based on traffic density as the service measure serves only the supply-side requirements and therefore they inferred that it does not adequately reflect the perception of the users on the QoS being provided. Moreover, traffic densities measured in PCU values that are static over a range of possible roadway and operational conditions do not adequately capture the heterogeneities arising out of situations such as platooning on a highway where, for the same traffic density, the driver of a following vehicle in a platoon would feel more constrained as compared to a scenario where the vehicles are more evenly spread over the road space. Thus, they felt that platoon characteristics would be more suitable as service measures especially under mixed traffic conditions.

While analyzing for the critical headway using the mean relative speed method, they observed that only the type of follower vehicle in a platoon has influence over relative speed while the type of platoon leader has got almost no effect. They divided the traffic stream in two types of vehicles based on their lengths viz. passenger cars (PC, length of vehicle $\leq 5.5 \mathrm{~m}$ ) and heavy vehicles (HV, length of vehicle $>5.5 \mathrm{~m}$ ). They utilized both the mean relative speed and exponential headway model methods to identify the critical headways for both types of vehicles when they are acting as followers in a platoon situation. Accordingly, they arrived at critical headways as 3 and $4 \mathrm{~s}$ for PC and $\mathrm{HV}$ as followers in a platoon, respectively.

To identify the most suitable service measure from all the platoon characteristics viz. platoon rate (number of platoons per hour on a road section), platoon size (average 
number of vehicles in a platoon) and percentage of following vehicles, they plotted the above platoon characteristics versus the observed traffic volume (in vehicles/h) for a study location on Tomei Expressway, which connects the city of Nagoya in Japan to the capital city of Tokyo. They observed that the platoon rate can exhibit variation based on the opportunity available for carrying out lane changing maneuvers. When the volume is low and there is little restriction on lane changing, the platoon sizes are smaller but the rate of platoons would be higher. However, with increasing traffic volume while the size of platoons will increase, both the opportunities for lane changing and the rate of platoons will decrease. Thus, based on platoon rate they devised four levels of service corresponding to freeflow, partial constraint-flow, constraint flow and congested flow conditions as depicted in Fig. 1 for typical expressways in Japan. The associated average platoon sizes for the proposed LoS as per Surasak et al. [6] are furnished in Table 5.

Indonesian HCM also utilizes platoon characteristics viz. degree of bunching, which is defined as the ratio of flow of vehicles travelling in platoons to total flow; degree of saturation, which is essentially the $V / C$ ratio; and mean operating speed to determine what they call the levels of performance of an undivided two-lane interurban road [7]. They adopted $5 \mathrm{~s}$ as the critical headway for determining the existence of a platoon. However, in the case of

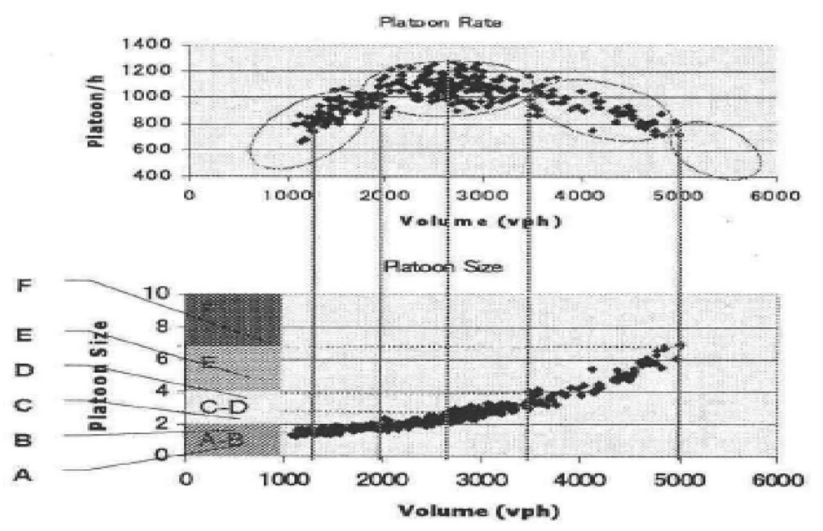

Fig. 1 LoS criteria according to platoon rate [6]

Table 5 LoS criteria for expressways in Japan

\begin{tabular}{ll}
\hline LoS & $\begin{array}{l}\text { Average platoon size } \\
\text { (no. of vehicles/platoon) }\end{array}$ \\
\hline Free-flow & $1.0-2.0$ \\
Partial constraint-flow & $>2.0-4.0$ \\
Constraint-flow & $>4.0-7.0$ \\
Congested-flow & $>7.0$ \\
\hline
\end{tabular}

Table 6 Level of performance criteria for multilane carriageways as per Indonesian HCM

\begin{tabular}{lcl}
\hline$Q_{\mathrm{D}}($ vehicles $/ \mathrm{h})$ & $Q_{\mathrm{V}} / C$ & Speed $($ in $\mathrm{km} / \mathrm{h})$ \\
\hline 0 & 0.00 & 70 \\
550 & 0.10 & 69 \\
1,100 & 0.20 & 68 \\
1,650 & 0.30 & 65 \\
2,200 & 0.40 & 64 \\
2,750 & 0.50 & 62 \\
3,300 & 0.60 & 59 \\
3,850 & 0.70 & 56 \\
4,400 & 0.80 & 52 \\
4,950 & 0.86 & 50 \\
5,500 & 0.96 & 43 \\
6,600 & $>1.00$ & \\
\hline
\end{tabular}

multilane divided carriageways, they advocated the use of only the degree of saturation (i.e. $\left[Q_{\mathrm{V}} / C\right]$ ) and the mean operating speed (in $\mathrm{km} / \mathrm{h}$ ) as performance measures. Accordingly, the levels of performance of a four-lane divided carriageway on a flat terrain as per the Indonesian HCM are given in Table 6 [7]. They do not categorically provide any lettering to the various levels of performance which, for particular roadway and terrain types, are divided according to the average annual daily traffic (AADT) or design hourly volumes $\left(Q_{\mathrm{D}}\right)$. They suggested that if the degree of saturation for a road is too high for a given AADT or $Q_{\mathrm{D}}$ level, then the cross-section design of the road needs to be revised.

Chinese Highway Capacity Study also followed exactly the same approach as the Indonesian HCM for determination of the level of traffic performance of a roadway facility [8].

\section{LoS Based on the Combination of Traffic Parameters}

Marwah and Singh [9] made use of an indigenous simulation model to estimate the LoS for a typical four lane divided urban carriageway and the data for the calibration of the model was collected in the city of Kanpur. Several performance measures were considered for analysis during each simulation run which are given below:

- Journey speed distribution of different vehicle types.

- Mean acceleration noise for different vehicle types. Acceleration noise of a vehicle was defined as the standard deviation of the variation about the mean acceleration.

- Road concentration which was measured in the following three ways: 
Number of vehicles in the road section.

Road occupancy expressed as total vehicle area in relation to the road area.

Vehicle influence area expressed as proportion of road area.

- Overtaking/passing maneuvers with respect to different combinations of overtaking and overtaken vehicle types.

Simulation was performed for a specific benchmark traffic composition comprising $35 \%$ motorized and $65 \%$ non-motorized traffic. Defining $\operatorname{LoS}$ as a composite of several macroscopic performance measures, they zeroed in on the following service measures:

- Journey speed of cars since cars have the highest freeflow speeds, their speeds are more significantly affected by the increase in flow levels.

- Journey speed of motorized two wheelers motorized two wheelers have free-flow speeds only slightly lower than that of cars, they can maneuver very easily through the gaps in the traffic stream and also their proportion in the traffic mix is significant which lends weight to their journey speeds being used as a service measure.

- Concentration concentration or density defined in terms of number of vehicles per kilometer determines the space headway which itself influences the freedom to overtake/pass in a traffic stream. Congestion is directly defined by the concentration level.

- Road occupancy the ratio of physical area of the vehicles in the road section to the road area is an important parameter considering widely varying vehicular dimensions in a heterogeneous traffic mix.

Subsequently, they arrived at four distinct $\operatorname{LoS}$ in the stable flow region. The details of the same and the associated service and performance measure values are given in Table 7.

\section{LoS Based on Aggregated Microscopic Measures}

It was demonstrated that the LoS estimated using macroscopic measures such as traffic density and those estimated using aggregated microscopic measures such as overtaking ratio exhibited large variations. Therefore, it was considered that the latter is more appropriate as a service measure as it more closely maps the QoS perceived by the drivers. The basis of the argument was that LoS can be considered as the degree of satisfaction of the drivers with the driving conditions in a road section which, for any instance, is formed by the perception of speed, the degree of freedom to maneuver, the degree of safety, etc. All these can be considered to constitute utility parameters for a driver. It was then argued that a driver takes driving actions such that it can maximize his/her utility [10].

Kita developed a utility function for drivers for the case of an on-ramp merging section on an expressway using disaggregated choice modelling with time to collision (TTC) to the closest through car approaching from rear side and the remaining length of acceleration lane normalized by the driving speed as the input variables. The average of the instantaneous utility of chosen driving action over time on a road section was used as the service measure [10].

Kita and Kouchi [11] revealed that there may be a hierarchical structure in determination of QoS by drivers depending upon the scale of analysis viz. point-based, section-based and trip-based. They argued that the drivers form their perception about the QoS based on the microscopic driving conditions in their field of vision which influence their driving actions such as maintaining speed, acceleration, deceleration and lane changing at any instant of time. This is called the instant or point-basis utility function of the driver. The section-basis utility can then be derived by aggregating the point-basis utility.

\section{User-Based LoS Definition}

There is also another school of thought that strongly recommends that there should be a direct involvement of users of the facility in determining its LoS. Flannery et al. [12] showed that the LoS calculated as per US-HCM methodology could only explain $35 \%$ of the variance in the mean drivers' rating of an urban street and that there were several non-operational factors such as travel efficiency, sense of safety and aesthetics that exhibited strong and statistically

Table 7 LoS based on traffic parameters for typical four-lane divided urban road in Kanpur, India

\begin{tabular}{|c|c|c|c|c|c|c|c|}
\hline LoS & $\begin{array}{l}\text { Service } \\
\text { volumes } \\
\text { (vehicles/h) }\end{array}$ & $\begin{array}{l}\text { Mean journey } \\
\text { speeds of cars } \\
(\text { in } \mathrm{km} / \mathrm{h})\end{array}$ & $\begin{array}{l}\text { Mean journey speeds of } \\
\text { motorized two wheelers } \\
\text { (in } \mathrm{km} / \mathrm{h} \text { ) }\end{array}$ & $\begin{array}{l}\text { Ratio of car and MTW } \\
\text { journey speeds to their free } \\
\text { flow speeds }\end{array}$ & $\begin{array}{l}\text { Average } \\
\text { longitudinal } \\
\text { spacing }(\mathrm{m})\end{array}$ & $\begin{array}{l}\text { Maximum } \\
\text { density } \\
\text { (vehicles } / \mathrm{km} \text { ) }\end{array}$ & $\begin{array}{l}\text { Road } \\
\text { occupancy } \\
(\%)\end{array}$ \\
\hline I & 600 & 37 & 36 & 0.8 & 65 & 30 & 1 \\
\hline II & 1,800 & 28 & 27 & $0.6-0.8$ & 20 & 100 & 3.5 \\
\hline III & 3,000 & 23 & 22 & $0.5-0.6$ & 11 & 180 & 6.5 \\
\hline IV & 4,200 & 19 & 18 & $0.4-0.5$ & 6 & 320 & 12 \\
\hline
\end{tabular}


Table 8 LoS criteria as per Flannery et al. [14]

\begin{tabular}{lcc}
\hline LoS & $\begin{array}{l}\text { Max. density based } \\
\text { on driver ratings } \\
(\mathrm{pc} / \mathrm{mi} / \text { lane })\end{array}$ & $\begin{array}{l}\text { Max. density as } \\
\text { per US-HCM } \\
(\mathrm{pc} / \mathrm{mi} / \mathrm{lane})\end{array}$ \\
\hline A & 6 & 11 \\
B & 14 & 18 \\
$\mathrm{C}$ & 22 & 26 \\
$\mathrm{D}$ & 29 & 35 \\
$\mathrm{E}$ & 39 & 45 \\
$\mathrm{~F}$ & $>39$ & $>45$ \\
\hline
\end{tabular}

significant correlations with the mean drivers' rating. This latter conclusion was also confirmed by Washburn et al. [13] as they found that in addition to traffic density, drivers also considered operational factors such as speed variance and mean speed as a percentage of free-flow speed along with non-traffic related factors such as pavement quality and driver etiquette for determining QoS on rural freeways. Driver perceived LoS was also modeled using ordered probit models for rural freeway facilities in the US and the derived LoS thresholds were found to be significantly different from those given by US-HCM [14] and are presented in Table 8. Based on this it can be inferred that the population density and location of the freeway facility can also have a profound effect on the LoS thresholds as the rural drivers were more sensitive towards the increase in density.

Papadimitriou et al. [15] also sought to include the opinions of the road users of a freeway in Greece in the assessment of the highway QoS. They modeled the user perceived $\mathrm{LoS}$ with $\mathrm{V} / \mathrm{C}$ ratio as the only explanatory variable found to be significantly correlated to the response variable. Moreover, they adopted a piecewise linear form to explain the above relationship. They suggested that the perception about QoS is hugely dependent on the congestion tolerance levels of the drivers as low-tolerance drivers perceived a $V / C$ ratio equal to 0.70 as the lowest $\mathrm{LoS}$, whereas at the same point, high-tolerance drivers have only started perceiving some significant deterioration of traffic conditions.

\section{LoS Determination Based on Fuzzy Logic}

Recent research has also suggested that the current LOS estimation procedure is flawed because even though LOS is defined on the basis of precise values of measurable quantities, they are actually describing the user perception about a facility which is bound to involve imprecision and vagueness [16, 17]. To control for this vagueness in modelling exercise, Dell'Orco and Mellano [16] have

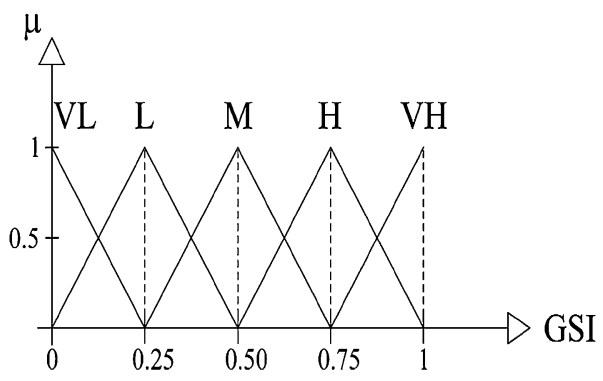

Fig. 2 Global satisfaction index as per Dell'Orco and Mellano

recommended using the concept of fuzzy logic. They developed a global satisfaction index (GSI) based on traffic quality (represented by the traditional LoS thresholds of density) and pavement quality (in terms of international roughness index, IRI) and represented it in the form of five fuzzy sets ranging from very low to very high. The fuzzy form of GSI is shown in Fig. 2.

Kikuchi and Chakraborty [17] also advocated recognition of the uncertainties involved in LoS definition and measurement of the service measure, and subsequent inclusion in the estimation process. This, they said, can be achieved by defining LoS categories as fuzzy sets so that the linguistic nature of LoS perception gets reflected in its definition. For including the effect of uncertainty, while collecting traffic data, they proposed considering the distribution of the observed service measure.

\section{Selection of Suitable Method for Indian Traffic Conditions}

The previous sections enumerated several possible service measures or alternative methods for LoS as adopted in different countries or places with traffic conditions that are at variance with the ones characterized by the US-HCM. All the above referred methods have their pros and cons. Hence, pinpointing a service measure or LoS method as the most suitable for application in India is a very difficult task. The problem is manifold in Indian case mainly because the kind of traffic and driver behavior that is witnessed on Indian roads is unique in nature.

For enabling the visualization of the kind of heterogeneity in traffic mix usually observed on Indian highways, the combined traffic composition data from eleven highway sections is shown in Fig. 3 [18]. The traffic data was collected on a normal working day on interurban sections of various four-lane divided national highways in the urban periphery of some of the major cities of India. The following nine vehicle types were observed on the above highway sections: 


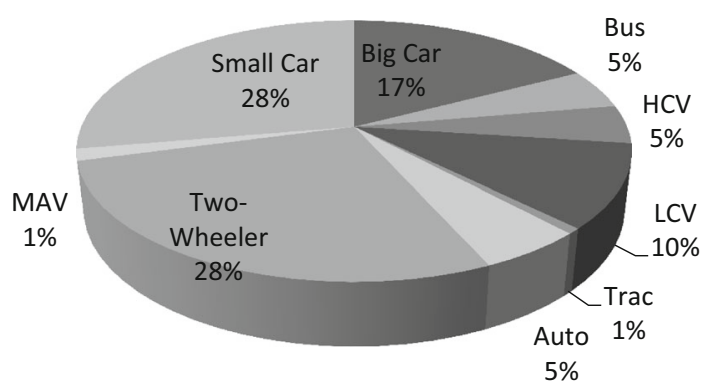

Fig. 3 Composition of traffic observed on a normal working day on various national highways in the urban periphery of some of the major cities of India

- Small cars (CS; cars with engine capacity $\leq 1,400 \mathrm{cc}$ ).

- Big cars $(C B$; cars with engine capacity $>1,400 \mathrm{cc})$.

- 3-Wheeled and 4-wheeled auto-rickshaws (Autos).

- Standard buses and articulated buses (Bus).

- Mini bus and light commercial vehicles (LCVs).

- Heavy commercial vehicles (HCVs; up to 2/3 axle heavy goods vehicles).

- Multi-axle vehicles (MAVs; $\geq 4$ axle $H C V s)$.

- Two-wheelers, i.e. motorcycles and scooters $(2 W s)$.

- Tractors with/without trolleys (Tractor).

The observed traffic on the above sections can be said to be typical, representing the highways of the same class. The important thing to note is the high proportion of twowheelers as well as three- and four-wheeled autos on the highway constituting one-third of the total traffic on the road. Now it can be argued that a two-wheeler that has a higher degree of maneuverability as compared to a car, and can easily move through the porous spaces between adjacent vehicles of higher categories, will have a different perception of the LoS offered by a highway section at a given time as compared to a car. The same thing can be said about three-wheeled autos which would require a lesser turning radius compared to cars and hence even under congested situations it can weave through the traffic in a much easier manner as compared to cars or other heavy vehicles. Additionally, the general indiscipline of the drivers of such slower vehicle-types, i.e. their failure in maintaining a constant position on the road, can lead to a lower perception of service quality by other road users even during free-flow conditions on a highway which witnesses higher proportion of slower vehicles in the traffic stream.

In India, the national highways are not fully accesscontrolled except for a few selected pockets primarily in the form of grade-separated stretches on some highways running for about 3-4 km. Moreover, most of the bus-stops on the highways are kerb-side and bus-bays, or even truck laybys are very infrequent on Indian highways. Significant quantum of pedestrian activity can also be observed adjoining the highways in the vicinity of hamlets located alongside and thereby contributing to significant roadside friction on Indian highways. All these factors combine to keep the users' expectation of highway performance moderated.

Apart from the factors internal to traffic stream, there are several external factors as well which are distinct from those found in the developed world and may have an effect on the perception of service quality among Indian road users. Low levels of adherence regarding rules of enforcement also play their part in defining Indian perception of the road users towards highway service quality. This point is further illustrated with the help of Fig. $4 \mathrm{a}$ and b. Figure $4 \mathrm{a}$ highlights a case where the side-drain has been deliberately filled with sand over some portion to construct a makeshift access road to the adjacent roadside establishment, which in this particular case is a hotel-cumrestaurant on the Delhi-Jaipur section of NH-8. Ribbon development along the highways is a common phenomenon in India and hence such scenes are more the norm than exceptions. In fact, if there are no roadside developments on a highway, it may lead to a negative sentiment among drivers as designated resting places for long-distance drivers are rarely incorporated on the ground in our highways.
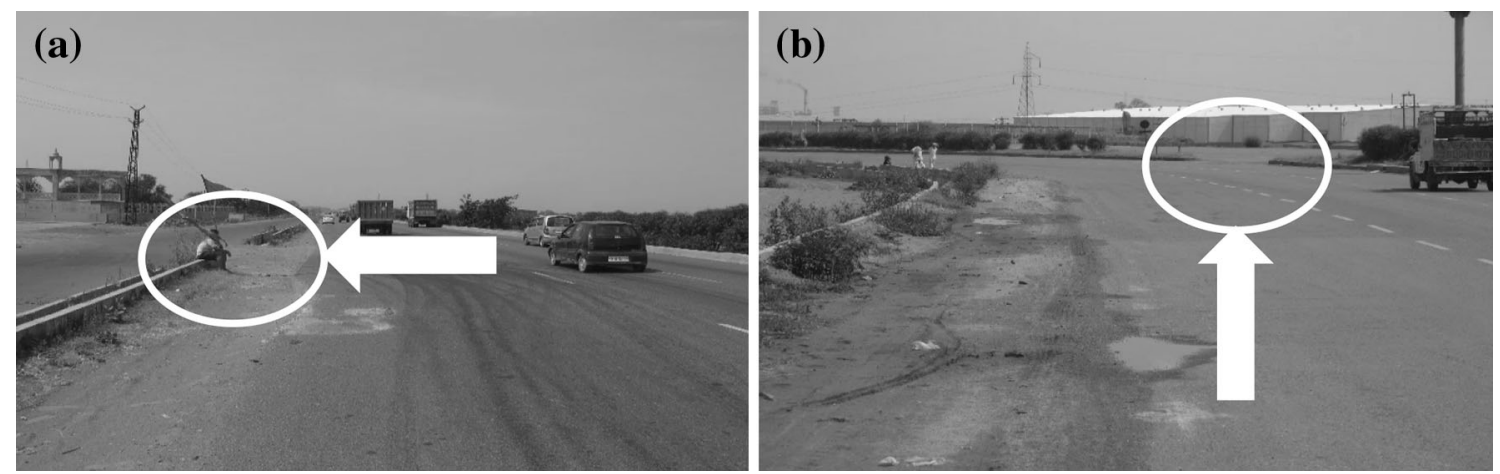

Fig. 4 a, b Typical examples of design and operation anomalies commonly observed on Indian highways 
Figure $4 \mathrm{~b}$ illustrates a curious case where an uncontrolled intersection has been provided just at the beginning of the horizontal curve seen in the image in the up-direction (or the end of the curve in the down-direction) in order to provide access to the industrial area seen on the righthand side in the image. High access point density and therefore frequent interruptions to traffic are commonplace on such highways. From a LoS perception point-of-view, such situations may elicit varying responses. For an occasional user, the obstruction due to turning traffic at such unexpected intersections may constitute a safety risk and an inconvenience and hence may lower his/her perception of the service quality of the highway segment. The regular users of the facility who, although, are not using this intersection, may have a higher tolerance for such an obstruction and hence a higher perception of service quality. Lastly, for the users who frequently use the intersection for making turns, such a provision may prove to be a big convenience since otherwise they may have to travel longer to make U-turns and hence they may report a still higher LoS for the highway segment.

A service measure adopted for Indian multilane interurban highways should also reflect the fact that users may have different perceptions towards the service quality at different times of a day. With prior knowledge shaping the sensitivity of the users to traffic conditions around them, they may be more willing to tolerate higher congestion, lower maneuverability and lower speeds during day hours than in the night hours leading to different $\operatorname{LoS}$ being assigned to the same facility during different times of the day for a given traffic condition. This perception may also be affected by the spatial proximity of the highway segment to an urban center with people being more predisposed towards encountering higher traffic densities near urban areas.

In the backdrop of the above discussion, an evaluation of the possible service measures with specific focus on their applicability on Indian highways is summarized in Table 9. While advantages for each of the service measures have been provided, the challenges to their adoption have been deduced based on the following two metrics:

- Ease of measurement/derivation - to gauge its usability for the highway professionals as a planning tool

- Ease of perception by road users-to gauge its ability to provide feedback regarding user-perceived LOS as a further aid in the planning process

Further since the paper is an outcome of the research being conducted under the Indo-HCM project, which employs traffic data collection through video-recordings as the chosen method of data collection, Table 9 also specifies whether data collection for a particular performance measure is possible through video recordings or additional methods are required for the same.

From Table 9, it can be seen that specifying a single service measure for use on Indian multilane interurban highways is quite difficult based only on literature review. Anyway, congestion (based on 'variations in speed' measures) can be recommended to be further studied as a service measure for broader applications in India. In addition to above, no study was found using components of congestion other than intensity, such as duration, spatial extent and frequency of recurrence, as service measures in Indian conditions. Therefore, it is recommended to study these components of congestion as performance measures as well for LoS determination on Indian highways.

Platoon characteristics can also describe user experience to a greater degree of accuracy in India, as platooning can occur on Indian multilane interurban highways even in free-flow conditions due to undisciplined movement of large vehicles. Therefore, if the challenges mentioned with regard to the use of platoon characteristics as service measures are met, they can also be a viable option to be studied in the Indian context.

On the other hand, measures such as non-operational factors can at best be used as additional performance measures to explain greater variations in user perception especially in Indian conditions. Attempts should also be made to include the effect of uncertainties in human decision-making through the use of fuzzy-logic or driverbased LoS definitions in future versions of the Indian Highway Capacity Manual.

\section{Number of LoS Categories Required}

Another point that merits discussion is regarding the number of LoS categories that are required to qualitatively characterize the traffic flow. Since the LoS seeks to represent the user's perception about the service quality, it is indeed intriguing to know whether the users are actually able to distinctly perceive the six LoS as professed by the US-HCM. Investigating this aspect, Papadimitriou et al. concluded that on the whole road users did not perceive more than three levels of service and that the perceived thresholds of the LoS were not equidistant as assumed by the US-HCM [15].

A survey of various state DOTs in the USA regarding the appropriate number of LoS categories required for design and evaluation of facilities was also carried out [17]. It was observed that $35 \%$ of the respondents felt that six LoS categories were not required and some were of the opinion that $\operatorname{LoS} A$ and $B$ are practically redundant and hence should be merged with the LOS C [17]. This observation is also in line with the conclusions arrived at by Papadimitriou et al. [15]. 


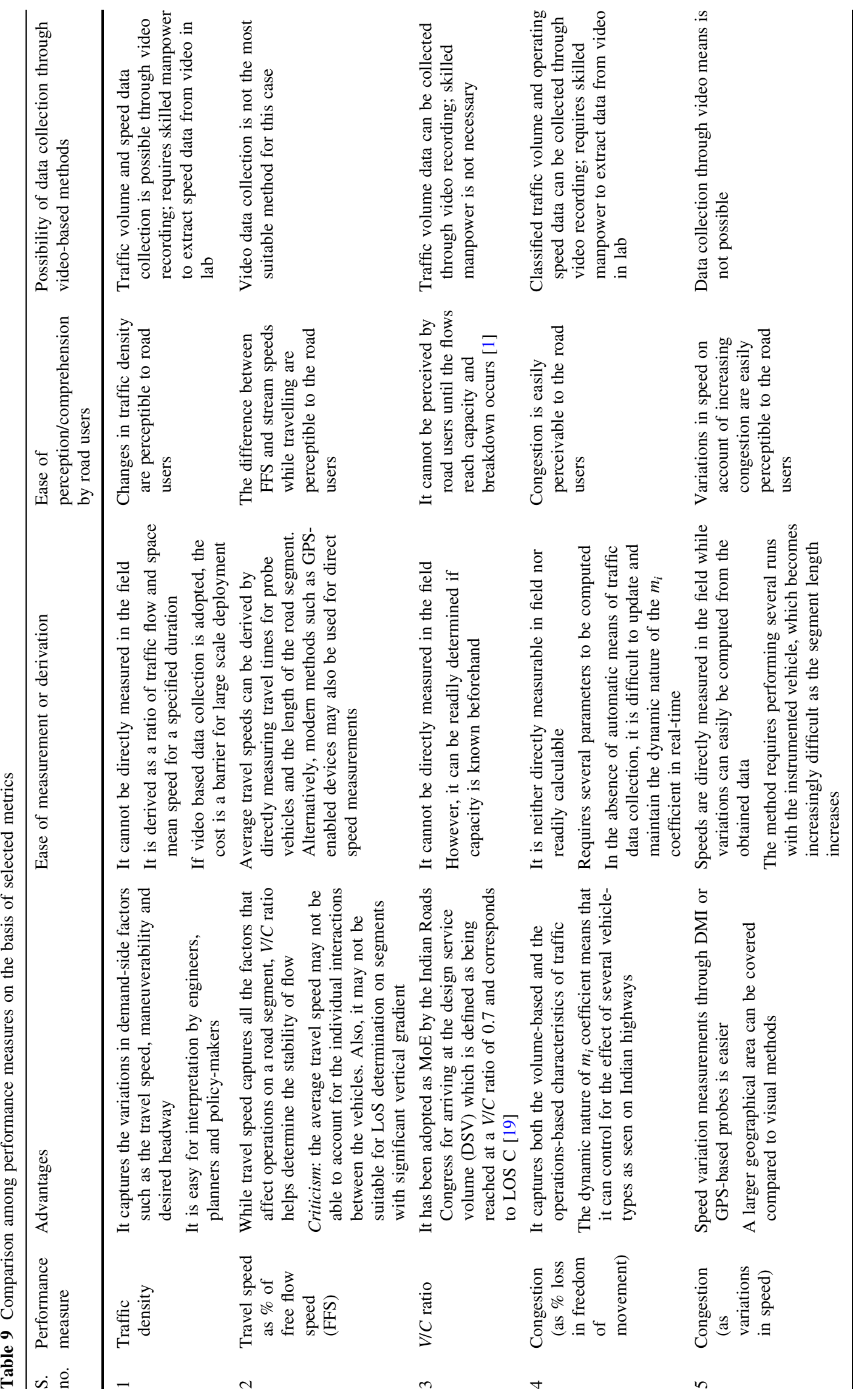




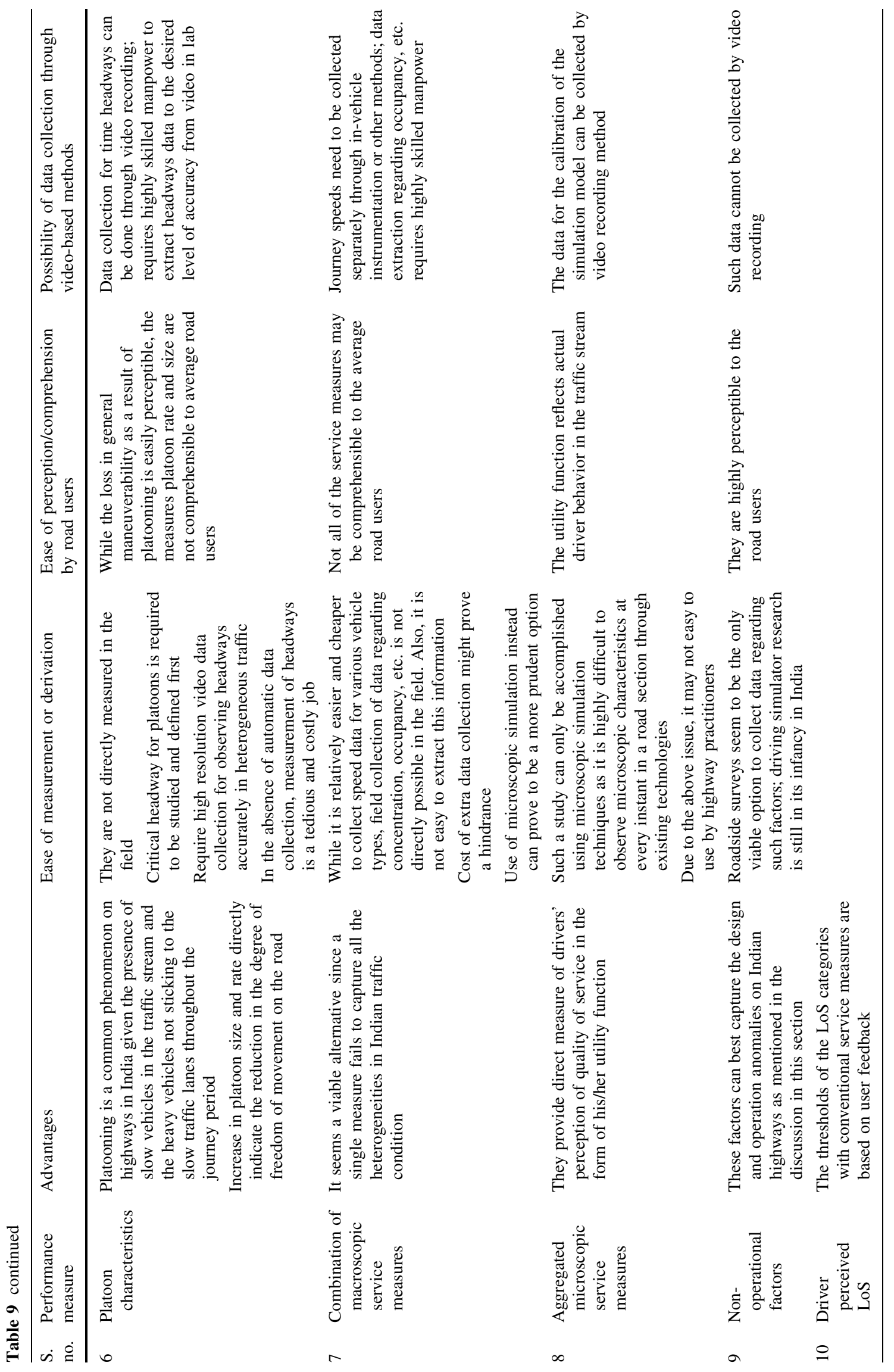


Indeed, if we critically survey the results obtained in all the studies cited in this paper, we get to see that the number of LoS categories required is quite closely linked with the service measure that has been selected for evaluating the facility performance. Moreover, since there is wide variation in vehicle-types, even if car users do perceive six different LoS the same may not be true for other vehicle types especially two wheelers and autos.

Although it becomes a matter of scientific enquiry as to how many LOS categories should finally be adopted and any further discussion in this regard has to be supplemented with investigation based on actual data (e.g. clustering analysis was performed to arrive at the appropriate number of categories by Patel and Joshi [3]), one thing becomes clear from the above review of literature is that the six LOS categories as prescribed by US-HCM may not be applicable for Indian highway conditions.

\section{Conclusion}

The paper rigorously discussed a broad set of methodologies that are aimed at definition of service measure(s) and/or estimation of LoS criteria. It is a difficult task to settle upon one service measure that can accurately take into account the several heterogeneities inherent in traffic operations on Indian highways. However, for a start, the measures reviewed herein can be evaluated for inclusion in the LoS estimation process in India. As for the number of LoS categories that should be adopted, based on the exhaustive review of the literature, it is felt prudent to explore varying combinations of three to five categories of LoS in the stableflow region as part of the ongoing Indo-HCM study.

\section{References}

1. Highway Capacity Manual (2010) 5th edn. National Research Council, Transportation Research Board, Washington D.C.

2. Highway Capacity Manual (2000) 3rd edn. National Research Council, Transportation Research Board, Washington, D.C.
3. Patel CR, Joshi GJ (2012) Capacity and LOS for urban arterial road in Indian mixed traffic condition. Proc Soc Behav Sci 48:527-534. doi:10.1016/j.sbspro.2012.06.1031

4. Maitra B, Sikdar PK, Dhingra SL (1999) Modeling congestion on urban roads and assessing level of service. J Transp Eng 125(6): 508-514. doi:10.1061/(ASCE)0733-947X(1999)125:6(508)

5. Anjaneyulu MVLR, Nagaraj BN (2009) Modeling congestion on urban roads using speed profile data. J Indian Roads Congr 549:65-74

6. Surasak T, Okura I, Nakamura F (2001) Study of platoon characteristics on a multi-lane expressway. Infrastruct Plan Rev 18(5):909-918

7. Indonesian Highway Capacity Manual (1993) Directorate General of Highways, Jakarta, Indonesia

8. Bang KL, Bergh T, Carlsson A, Hansson A, Ronggui Z (1999) Highway capacity study, final report and capacity guidelines. National Highway Project of Peoples Republic of China, Hebei and Henan Provincial Communications Departments

9. Marwah BR, Singh B (2000) Level of service classification for urban heterogeneous traffic: a case study of Kanpur metropolis. In: Fourth international symposium on highway capacity, Hawaii

10. Kita H (2000) Level-of-service measure of road traffic based on the driver's perception. In: Fourth international symposium on highway capacity, Hawaii

11. Kita H, Kouchi A (2011) A utility-based evaluation method on the perceived quality of traffic service. Proc Soc Behav Sci 16:820-831. doi:10.1016/j.sbspro.2011.04.501

12. Flannery A, Wochinger K, Martin A (2005) Driver assessment of service quality on urban streets. Transp Res Rec 1920:25-31

13. Washburn S, Ramlackhan K, McLeod D (2004) Quality-of-service perceptions by rural freeway travelers: exploratory analysis. Transp Res Rec 1883:132-139

14. Flannery A, McLeod D, Pedersen NJ (2006) Customer-based measures of level of service. ITE J 76(5):17-21

15. Papadimitriou E, Mylona V, Golias J (2010) Perceived level of service, driver, and traffic characteristics: piecewise linear model. J Transp Eng 136(10):887-894

16. Dell'Orco M, Mellano M (2013) A new user-oriented index, based on a fuzzy inference system, for quality evaluation of rural roads. Comput Aided Civ Infrastruct Eng 28(8):635-647. doi:10. 1111/mice. 12021

17. Kikuchi S, Chakraborty P (2007) Frameworks to represent the uncertainty when determining the level of service. Transp Res Rec 1968:53-62

18. Yadav A, Arun A, Velmurugan S (2014) Roadway capacity estimation for multi-lane interurban highways in India. In: Colloquium on transportation systems engineering and management, CTR, CED, NIT Calicut, India, 12-13 May 2014

19. IRC-64 (1990) Guidelines for capacity of roads in rural areas. 1st Revision. Indian Roads Congress, New Delhi 